\title{
Editorial: Journal of Theoretical and Applied Electronic Commerce Research is Now Included in the Social Science Citation Index
}

\author{
Narciso Cerpa \\ Editor-in-Chief \\ May 2017
}

\section{Social Science Citation Index}

This is the second issue of the eleventh volume of the Journal of Theoretical and Applied Electronic Commerce Research (JTAER). In this editorial we: (a) congratulate all those who are part of JTAER for the inclusion of the journal in the Social Science Citation Index; (b) briefly show increasing number of citations per year; (c) announce a forthcoming special issue; and (d) we make a call to those interested in becoming reviewers or members of the editorial board of JTAER.

Through our web-based system we have already communicated to our collaborators that JTAER has been included in the Social Science Citation Index (SSCI) of ISI Thomson Reuters. This is recognition to the quality of the research published at JTAER. Without your participation (editorial board members, reviewers, authors, and readers) this achievement would not be possible. Thanks to all of you for your valuable contribution to the development of JTAER

This is another good reason for you to consider publishing the results of your research in our scientific journal if you have results that help to improve the comprehension of our electronic commerce field. This research can be a new method, rationalization or reinterpretation of published results, review of a topic, or original research in a particular area. For example, empirical research, case studies, surveys, systematic literature reviews, etc.

\section{Citations}

We are continuously monitoring the citations and we have observed that the number of citations to JTAER has steadily increased through the years, and these citations come from many different journals that are indexed in the ISI and/or the Scopus data bases, showing JTAER's relevance and acceptance by researchers of a wide research community (see Table 1).

Table 1: Number of citations per year

\begin{tabular}{|l|l|l|l|l|l|l|l|l|l|}
\hline Year & 2008 & 2009 & 2010 & 2011 & 2012 & 2013 & 2014 & 2015 & 2016 \\
\hline Citations & 26 & 100 & 128 & 174 & 171 & 212 & 244 & 290 & 292 \\
\hline
\end{tabular}

Since the inclusion of JTAER in the SSCI we have attracted more submissions from authors implying better quality of the published papers through more competition in a larger pool of available papers. At the same time, the quality of our review process has established high standards and as a result, good quality papers. We need to keep our fast turnaround time of the reviewing cycle since it is a quantitative indicator used by many journals to measure the performance of the reviewing process and often attracts more submissions from authors. Therefore, we need more reviewers and also members for our Editorial Board.

\section{Reviewers and Editorial Board Membership}

Due to the journal's growth we currently need more reviewers and also have a few vacancies on the Editorial Board of JTAER. Reviewers will be asked to review three to four papers a year, and will be considered in the future for an Editorial Board membership depending on the quality of their research reports. Those interested in becoming members of the editorial board should have experience with scholarly journals or other types of publications. The basic responsibilities of the Editorial Board membership include: contributing to defining the strategic direction, policies and procedures for the journal; reviewing at least four papers per year; suggesting ten to twenty good reviewers in a period of two years; organizing a special issue in a period of three year; attracting quality papers; suggesting other Editorial Board members who are team players; proposing and attracting good reviewers; writing a technical editorial; among others.

The JTAER committee seeks individuals who are considered research leaders in their discipline. The Editorial Board membership's applicants should be experts in technical and/or business related issues of electronic commerce. Each candidate or nominee for the Editorial Board position is requested to provide the following information: (a) current CV including information about qualifications, academic and administrative positions, publications, awards, professional affiliations and activities, and other relevant items; (b) statement of interest, potential contribution (not more than one page), and availability to serve as member of the Editorial Board. We will give preference to those candidates from 
countries that are not represented in JTAER's Editorial Board yet.

If you have interest in contributing to our journal and credentials in the electronic commerce field and would like to serve as a reviewer or becoming a member the Editorial Board, please contact the Editor-in-Chief at ncerpa@utalca.cl.

\section{Forthcoming Special Issue}

We have announced a special issue for 2018. This issue will be dedicated to Dark Sides of Social Commerce and will be guest edited by Babuk Abedin (University of Technology Sydney) Sergiu Dascalu (University of Nevada) and Ghassan Beydoun (University of Technology Sydney). The full manuscript submission deadline is the $1^{\text {st }}$ of November 2017.

We are continuously evaluating and considering new proposals for Special Issue on current and innovative research areas of interest to the electronic commerce community. Proposals are evaluated by the Editorial Committee based on the interest that researchers and practitioners may have on the proposed topic; leadership and capacity of the potential authors on the proposed topic; and the perceived probability of success of the proposal. Proposals must include at least two guest editors from two different continents, and must be submitted to the Editor-in-Chief (ncerpa@utalca.cl) 